\title{
ICTS AND GLOBAL WORKING IN A NON-FLAT WORLD
}

\author{
Geoff Walsham \\ Judge Business School \\ University of Cambridge \\ Cambridge, U.K.
}

\begin{abstract}
This paper rejects the hypothesis of Thomas Friedman that ICT-enabled globalization is driving us toward a flat world. Instead, it is argued that the world remains uneven, full of seams, culturally heterogeneous, locally specific, inequitable, not well-integrated and constantly changing. This argument is supported by an analysis of three areas of ICT-enabled global working, namely global software outsourcing, global IS roll-out, and global virtual teams. The paper then builds on these analyses to put forward an agenda for future IS research on ICTs and global working based on three research themes: identity and cross-cultural working; globalization, localization and standardization; and power, knowledge, and control. The paper concludes that the area of ICTs and global working offers the IS field a major research opportunity to make a significant contribution to our understanding of a set of crucial issues in our more globalized world.
\end{abstract}

Keywords Flat world, globalization, global software outsourcing, global IS roll-out, global virtual teams, IS research agenda, identity, cross-cultural working, standardization, power, knowledge, control

\section{INTRODUCTION}

The changes taking place in the global economy, including those in the burgeoning services component, are the subject of much debate by a wide range of commentators including journalists, practitioners, and academics. In the first of these categories, one book which has enjoyed remarkable success in terms of sales is The World is Flat: A

Please use the following format when citing this chapter:

Walsham, G., 2008, in IFIP International Federation for Information Processing, Volume 267, Information Technology in the Service Economy: Challenges and Possibilities for the $21^{\text {st }}$ Century, eds. Barrett, M., Davidson, E., Middleton, C., and DeGross, J. (Boston: Springer), pp. 13-25. 
Brief History of the Twenty-First Century by Thomas Friedman (2005). According to Friedman, information and communication technologies and globalization are driving us toward a flat world with a level playing-field for global competition, in which geography, distance, and even language become irrelevant. The thrust of this paper is to argue against Friedman that, although ICTs and globalization are indeed crucial to the global transformations that are taking place, the world is not flat.

Friedman's book has already produced much counter-argument although not, as far as I am aware, in the information systems field. For example, Leamer (2007) provides a detailed critique from the point of view of an economist. In addition to arguing that Friedman's definition of a flat world is vague, he takes issue with the notion of a relationship-free world in which every economic transaction is contested globally. Leamer argues that relationships matter and that the world is highly uneven in terms of advantages that individuals, groups, and societies enjoy. It is particularly ironic that Friedman uses India as a frequent example of the leveling of the playing field, a society of increasing wealth for the privileged, but where approximately one in two women are illiterate and one in two children under five are malnourished (UNICEF statistics, http://www.unicef.org/infobycountry/india_india_statistics.html).

Practitioners have also engaged with the nature of ICT-enabled global transformation and, unlike Friedman, the rhetorical hype tends to be less florid and the approach more down-to-earth. A good example is provided by Palmisano (2006), the chairman and chief executive of IBM. Palmisano argues that the term multinational has been superseded and should be replaced by the notion of a globally integrated enterprise. He says that such enterprises "have been made possible by shared technologies and shared business standards, built on top of a global information technology and communications infrastructure" (p. 19). Although, at first sight, this might sound unproblematic as a description of modern-day enterprises such as IBM, it is phrases like "globally integrated" and "shared business standards" that I wish to challenge in this paper.

In opposition to Friedman, and to some extent Palmisano, this paper argues that the world is uneven, full of seams, culturally heterogeneous, locally specific, inequitable, not well-integrated, and constantly changing. In the following sections, three IS research areas are used to illustrate this argument, namely global software outsourcing, the global roll-out of information systems, and global virtual communities. In each of these areas, the aim is not to produce a full literature review, but rather to use selected articles to illustrate and analyze the non-flat nature of ICT-enabled forms of global working. The paper then builds on these analyses to produce an agenda for future research on ICTs and global working based around three research themes. Finally, some conclusions are drawn on the high potential value of research in such areas for the IS field as a whole.

\section{GLOBAL SOFTWARE OUTSOURCING}

The outsourcing of software and other services on a global basis has become an emblem of globalization and, for Friedman and others, a prime example of the new flat world. However, any detailed analysis of particular global software outsourcing cases presents a much more uneven picture of complex and evolving relationships between the outsourcing partners, including issues of cross-cultural contradiction and sometimes conflict. For example, Walsham (2002) uses structuration theory as a basis for the 
analysis of two case studies of global software production and use. The first involved a team of Indian software developers working in a Jamaican insurance company, and the second the use in India of geographical information systems software originally developed in the United States. Walsham shows that cultural differences in areas such as detailed work patterns, and ways of conceptualizing space, created contradictions and tensions in such global relationships, resulting in the first case in outright conflict and, in the second case, in major problems of implementation and use. There is no feel of "flatness" in these cases, although the author discusses the concept of negotiated culture (Brannen and Salk 2000) as a possible way forward in trying to address cross-cultural issues and difficulties.

Krishna et al. (2004) based their analysis of ways of managing cross-cultural issues in global software outsourcing on a wide range of cases that the authors had carried out on outsourcing from North America, Western Europe, and Japan to software suppliers in developing countries, with a particular emphasis on India. The primary conclusion from their research is that working across culture when outsourcing software production is not a trouble-free process. They identify different work practices, different modes of communication and the cultural adaptation of bridgehead teams as examples of difficulties that arise. They suggest ways of approaching these difficulties through, for example, the strategic choice of which projects to outsource, the use of common systems and processes, attempts to move toward a negotiated culture of work practice, and staff education and training. Many of these approaches can be argued to have been reasonably successful since global outsourcing continues to grow, but the picture that is produced is certainly not that of the globally integrated organization based on shared business standards.

Nicholson and Sahay (2001) describe a longitudinal case study of outsourcing from a UK company to an Indian software supplier. In addition to discussing cross-cultural issues and the changing nature of the business relationship over time, as in the articles above, the authors also make an interesting set of comments on the nature of globalization itself. They argue that global software outsourcing can provide examples of how the local interacts with the global in a two-way manner. They illustrate this by an example of an embodied software methodology, developed in the West but taken up in India, which was then re-embedded into the British context by the Indian programmers. The point is that globalization should not be seen as some top-down behemoth which is flattening the world, but rather as a complex and evolving process in which global-local interaction is two-way with often unforeseen outcomes.

The book by Sahay et al. (2003) is perhaps the most substantial contribution to the literature to date on the nature of global IT outsourcing relationships. Much of the research underpinning the book looked at outsourcing to India, widely regarded as the leader in the field. However, it is clear from the book that India's relative success has not been achieved without lengthy and sometimes painful learning processes on the part of those involved on both sides of outsourcing alliances. The authors identify several micro-level themes, reflecting tensions in such alliances: shifting identity, the complexities of knowledge sharing, the limits and benefits of standardization, issues of power and control, and the challenges of cross-cultural communication. It is not possible to discuss all of these here, so I will focus on the single theme of shifting identity in the rest of this section. 
One argument that is often made by those who see the world as flattening is that people across the globe are becoming more similar in their interests, attitudes, and perhaps, therefore, identity. If one believes this argument, then surely Indian software workers who travel and work across the globe would provide strong evidence of this. This makes the work of D'Mello $(2005,2006)$ particularly interesting, since her research involved an extensive and prolonged engagement with such "global workers" on the theme of "selves and identities of IT professionals in India." In D'Mello (2005), she argues that these workers are engaged in complex identity shifts, and tensions of identity. The latter are brought about by, for example, potential conflicts between Indian group and family orientation and the Western-oriented individualism encountered in their client organizations. The author nicely reverses the standard cliché by arguing that such workers often "think local but act global."

Now it could be argued that the Indian software workers are nevertheless nearer to their western colleagues in terms of identity than they were in previously less-globalized eras. However, processes of hybridization produce much diversity as history has surely shown us, and the new hybridized Indian software workers are one example of this. Putting it more strongly, and borrowing from Haraway (1991) on cyborgs, I would argue that we are all identity hybrids now. D'Mello (2006) expresses this as follows for the workers she studied:

organizations, industries and marketplaces are milieus deeply imbued with personal, social and existential structures and processes which evoke a range of feelings and subjectivities, and influence workers' sense of self and identity. I argue that, in global work contexts, workers construct their selves and identities from both global and local elements' (p. ix).

At the level of the individual, therefore, the world again does not look flat.

\section{GLOBAL INFORMATION SYSTEM ROLL-OUT}

A second area concerned with ICTs and global working is that of the global roll-out of information systems in particular organizations. The term roll-out is worth noting. The image which is evoked is of a smooth process, like rolling out a carpet across a flat floor. As my subsequent examples will attempt to show, the global roll-out of IS is normally anything but smooth, and the floor is anything but flat. Perhaps the wide use of the term roll-out reflects wishful thinking on the part of management that the process will be smooth, reinforced by vendors of software or services who wish to present global IS development in this way?

Joshi et al. (2007) describe and analyze the global roll-out of an information system, called ISX, to a communications and media group across a global pharmaceuticals company. The concept was to provide group members, independent of where they were located or their specific role, with a standard means to support key aspects of their work such as handling media enquiries, maintaining contacts databases, and generating news and information about the company and its products. The system was not a failure in the sense that it was used by many communicators across the organization and provided some degree of global integration amongst the widely separated groups in different countries. However, the ISX system was less successful than its designers intended, 
since its use was less widespread than they had hoped, and its global reach was limited by factors such as local relevance and cultural fit. For example, the communicators group in Japan used a Japanese-language system to support their interactions with local media, and the global system written in English could not cope with this. Secondly, and more subtly, the new system was aimed to provide better lateral information flows across the global organization, but the structured and hierarchical nature of the organization inhibited this form of global knowledge sharing.

Rolland and Monteiro (2002) describe a case study of the global roll-out of an information system in a maritime classification company working in over a hundred countries. The IS was designed to support the surveying of ships in order to assess their condition, to be used, for example, for insurance purposes. Rolland and Monteiro discuss the need for a "pragmatic balance" between universal standards and local specificity. They describe how this was achieved in their case by largely invisible work on negotiations, work-arounds, tinkering, etc. The authors argue that these approaches are not compensations for poor design but are necessarily required in all global IS infrastructures. So, global systems, according to them, are not seamless, integrated systems that provide common standards and approaches in all locations. Rather, continuing local work needs to be done to mold the systems to local specificities and these, in turn, affect the evolving global approach. In the words of the authors, "The real issue, we argue, is to analyze how global, never-perfect solutions are molded, negotiated, and transformed over time into workable solutions" (p. 96).

One of the most ubiquitous of global systems is enterprise resource planning (ERP) systems. These have been rolled-out in many organizations over the last 15 years. The success of these endeavors has undoubtedly been mixed (see, for example, Davenport 1998). The literature on ERP systems typically looks at case studies of particular organizations and echoes many of the points made earlier in this section, for example, on the difficulties of local relevance and cultural fit, and on the need for local negotiations, work-arounds, and tinkering. Referring briefly to the theme of the current paper, this literature alone surely refutes the notion of a flat world served by seamless integrated systems.

Nevertheless, ERP systems are widely used around the world, so some success has been achieved in making global solutions fit local conditions. An interesting strand of research looks at this issue from the opposite end to that of the user organizations, namely that of the ERP supplier. Pollock et al. (2003) argue the need to understand the "biography" of software packages such as ERP and the way that suppliers try to provide a "generic" product, whereas users try to accommodate tensions between that and local needs. In a later paper, Pollock et al. (2007) describe this work of the suppliers as "generification" work. The authors provided a detailed description of this process in the case of an ERP system aimed at supporting the administrative functions of universities. They made the point that generic packages such as this can and do serve diverse contexts. This is undoubtedly true, but two qualifying comments can be raised. First, there is an interesting question as to which users get most say in the generification process. In other words, how do power relations influence the final design and make the system more suitable for some than others? Second, Pollock et al. (2007) argue that diverse organizations and standard technologies can be brought together, but the question remains as to what the consequences are for the organizations, positive and negative. The generification of systems does not have "flat" effects across different organizations. 


\section{GLOBAL VIRTUAL TEAMS}

A third area of high relevance for contemporary forms of global working is that of global virtual teams. A precise definition of virtuality is hard to achieve (Crowston et al. 2007) but is normally taken to involve geographical dispersion, a dependence on electronic interaction, and sometimes a dynamism of structure (Gibson and Gibbs 2006). The addition of the qualifier global implies cultural diversity is also present. In terms of the non-flatness theme of this paper, the thesis in this section is not that global virtual teams cannot be made to work well in some cases, nor that global organizations should necessarily place less emphasis on them. Rather, the argument is that global virtual teams exhibit enormous variety and thus that any one-size-fits-all solution to their design, implementation, and management is unlikely to be successful.

An early article on global virtual teams by Dubé and Paré (2001), based on interviews with team leaders and members, pointed out difficulties brought about by the diversity of people in terms of culture, language, and IT proficiency. They also noted that accessibility to technology and its appropriateness in particular contexts were further problems that needed to be faced by global virtual teams. In another early article, Qureshi and Zigurs (2001) raise similar issues about the importance of culture and technology. They make the useful point that the nature of tasks faced by virtual teams differ greatly, and they say that their case study data supported the view that the teams that worked best involved tasks with a high level of structure and tasks requiring detailed teamwork.

Majchrzak et al. (2004) take a very positive view of virtual teams supported by technology based on interviews with 293 members of "successful" teams. It is worth noting that they did not obtain permission to talk to members of teams that were considered failures, so their sample is rather biased. Nevertheless, the article is a good counter to any technologically determinist view that virtual teams supported by ICTs are necessarily inferior to those supported by face-to-face encounters. Technologies found to be of high value included virtual work spaces, teleconferencing, and instant messaging. The authors emphasize that a lot of effort needed to be put in by the leaders to try to knit the teams together.

Kayworth and Leidner (2002) explore this theme of the importance of leadership in global virtual teams through a study of leadership effectiveness in multicultural student teams drawn from MBA students in Europe, the United States, and Mexico. The authors conclude that important attributes of effective leaders include being good mentors, having empathy with team members, prompt communication habits, and clear articulation of team roles and responsibilities. There is limited emphasis on technology in this study other than to note that web sites tailored to team members' needs seemed to work well.

The paper by Kankanhalli et al. (2007) is valuable in that it focuses on conflict episodes in global virtual teams rather than the somewhat rosier side of the picture that is painted by some of the authors above. Although based on work with student teams, which potentially limits the strength of their findings, it is clear that cultural differences between people from North America, Europe, and Asia were significant causes of team conflict. The article also discusses differences in task complexity affecting team outcomes but the results here are rather inconclusive. The discussion of technology is somewhat limited, other than noting, for example, that sending too many e-mails and slow responses can be problematic to teamwork. 
Although a full literature review has not been provided in this section, the examples suggest that the sum total of research on global virtual teams is currently rather thin. This view is supported by a substantial survey of the literature on virtual teams by Martins et al. (2004). The authors conclude that research on virtual teams to date, while valuable, had been relatively limited in scope, and based mainly on student laboratory studies. They identify a wide range of areas for further research on inputs, processes, outcomes and moderators of virtual teams, mentioning global virtual teams as a subset. In a recent short article focusing specifically on global virtual communities, Tan (2007) echoes this need for further research: "Although some preliminary research findings on virtual communities have been reported over the past few years, there is still a clear lack of coherent theoretical development and systematic empirical investigation on this topic" (pp. i-ii).

I move now to consider the topic of future research, not just for global virtual teams, but also for ICTs and global working more generally.

\section{FUTURE RESEARCH ON ICTS AND GLOBAL WORKING}

A key aim of the previous three sections has been to use the results of published research to argue that the world is a complex, uneven place, where relationships matter whether at the individual or organizational level. Diversity is everywhere and global working processes must adapt to this reality. ICTs are deeply implicated in all such processes, and thus vital to the contemporary world. Others have made similar points at greater length (e.g., Avgerou2002; Walsham 2001), but it seems that that the the of global diversity and unevenness needs to be reiterated in the face of the journalistic hyperbole of Friedman and others. A key implication for the IS research community is that ICTs and global working is an exciting research area with a relatively untapped potential for innovative and interesting research work.

Table 1 provides a summary of some common research themes across the three topic areas discussed above. These common themes are identity and cross-cultural working; globalization, localization and standardization; and power, knowledge, and control. Each of these themes is discussed below in terms of how future IS research could develop further understanding of the theme. In each case, some examples of specific research topics are identified together with a brief discussion of some relevant literature.

\subsection{Identity and Cross-Cultural Working}

Cross-cultural issues have been discussed in the IS literature to date as we have seen, but really the surface has been barely scratched with many countries not represented at all. What do we know in depth about outsourcing to China, IS roll-out in Nigeria, or global virtual team members in Brazil? In a related way, issues of identity in these contexts have received little attention in the IS literature to date. Now it could be argued that there are substantial non-IS literatures that deal with countries such as those above. These literatures can no doubt be used to help us understand issues of identity and crosscultural working in such contexts, but future research is needed to show us how this can 
Table 1. Common Research Themes Across the Topic Areas

\begin{tabular}{|c|c|c|c|}
\hline $\begin{array}{c}\text { Common } \\
\text { Themes }\end{array}$ & $\begin{array}{l}\text { Identity and Cross- } \\
\text { Cultural Working }\end{array}$ & $\begin{array}{c}\text { Globalization, } \\
\text { Localization and } \\
\text { Standardization }\end{array}$ & $\begin{array}{c}\text { Power, Knowledge, and } \\
\text { Control }\end{array}$ \\
\hline $\begin{array}{l}\text { Global } \\
\text { software } \\
\text { outsourcing }\end{array}$ & $\begin{array}{l}\text { - Cross-cultural } \\
\text { working not trouble } \\
\text { free } \\
\text { - Tensions of identity } \\
\text { of software workers }\end{array}$ & $\begin{array}{l}\text { Two-way local/ } \\
\text { global interaction }\end{array}$ & $\begin{array}{l}\text { - Complexities of knowl- } \\
\text { edge sharing } \\
\text { - Power and control issues } \\
\text { between outsourcers and } \\
\text { vendors }\end{array}$ \\
\hline $\begin{array}{l}\text { Global IS } \\
\text { roll-out }\end{array}$ & $\begin{array}{l}\text { - Local relevance and } \\
\text { cultural fit }\end{array}$ & $\begin{array}{l}\text { - Pragmatic balance } \\
\text { between universal } \\
\text { standards and local } \\
\text { specificity } \\
\text { - Generification of } \\
\text { software packages }\end{array}$ & $\begin{array}{l}\text { - Hierarchies deterring } \\
\text { global knowledge } \\
\text { sharing } \\
\text { - Power relations influ- } \\
\text { encing who has most say } \\
\text { in final design }\end{array}$ \\
\hline $\begin{array}{l}\text { Global } \\
\text { virtual } \\
\text { teams }\end{array}$ & $\begin{array}{l}\text { - Fit between tech- } \\
\text { nology and culture } \\
\text { - Cultural differences } \\
\text { as source of conflict }\end{array}$ & $\begin{array}{l}\text { High variety of global } \\
\text { virtual teams pro- } \\
\text { hibits one-size-fits all } \\
\text { solutions } \\
\text { - Nature of task impor- } \\
\text { tant in team success }\end{array}$ & $\begin{array}{l}\text { Role of leadership in } \\
\text { making global virtual } \\
\text { teams work }\end{array}$ \\
\hline
\end{tabular}

be done. As an example of such work, Ailon-Souday and Kunda (2003) discuss crosscultural working in an Israeli high-tech corporation undergoing a merger with an American entity. Their paper demonstrates how concepts of Israeli national identity were drawn on as a resource in order to deal with some of the social struggles which arose in cross-cultural working.

Cross-cultural working normally involves more than one country but, even within countries, there are important differences in identity and culture, despite the dull homogeneity implied by Hofstede's (1991) simplistic indices of national culture. A good example of this in the recent IS literature is provided by Miscione (2007). The author describes telemedicine practices in the Upper Amazon in northeastern Peru and shows how these western-inspired practices were frequently mismatched with the local culture in these areas and, in particular, with the definitions of health and illness employed by local communities and healers. The increasing importance of cultural diasporas scattered around the world further emphasizes the need to study within-country identity and cultural difference. Appadurai (1996) discussed such differences using the concept of imagination. He argued that people draw on contemporary sources, such as the media, and their own cultural histories to "annex the global" into their own "practices of the modern" through their imagination.

Drawing on existing concepts, such as those of Appadurai, is desirable in trying not to reinvent the wheel of theories of identity and culture when carrying out IS studies. However, IS studies have the potential in turn to contribute to broader research areas than those of the IS field alone. For example, D'Mello and Sahay (2007) extend their work on identity of Indian global software workers, referred to earlier in the paper, to discuss how geographical, social, and existential mobilities of these workers shape their relation- 
ship to place and to their identity. D'Mello and Sahay argue that their theoretical concepts of "mobility-identity" contribute to the call of the sociologist Urry (2000) for the development of a "sociology of mobilities."

\subsection{Globalization, Localization and Standardization}

Turning now to the future research theme of globalization and localization, there is a large literature upon which IS researchers can draw (e.g., Beck 2000; Castells 1996, 1997,1998 ) in order to inform our work. However, detailed IS studies can contribute a crucial dimension to our understanding of global/local processes in that technology is normally a key element of such processes, and detailed empirical studies are needed to extend our understanding of how this works. For example, there is much interest in the topic of knowledge sharing and knowledge management in global organizations. Although there is a sizeable literature on this topic area, most of it does not deal with the full diversity of global organizations with a few exceptions (e.g., Pan and Leidner 2003). This is perhaps understandable in that research access can be difficult when dealing with widespread global operations and research costs can be high. Nevertheless, we are getting a very partial picture of global knowledge sharing processes when we exclude large portions of the world from our studies.

A second example of a future IS research topic of high interest, with little published academic work to date, is the relationship between global working and the use of social networking technologies and other forms of user-driven web-based systems (McAfee 2006). One should not be carried away by the hype about Web 2.0 to believe, for example, that Facebook will solve the problem of cross-cultural collaboration, as one student suggested to this author recently. However, it would be equally foolish to neglect the potential of such technologies to support work in general, and global working in particular. Similarly, there is great interest (e.g., Jagun et al. 2007) in the potential for mobile technologies to provide relevant ICT-based services to relatively poor people in developing countries, to enable them to participate more fully in the globalizing world, where previous fixed technologies such as the landline phone and the fixed PC have not been widely available or used.

One important IS topic within the theme of globalization/localization is that of standardization and generification of software packages. Some work on this was discussed earlier in the paper, but again there is very little published work that extends beyond the context of a limited range of wealthy countries to the wider global arena, despite the fact that software such as ERP systems has spread across most of the world. An exception to this is the work known as the HISP program. Braa et al. (2007) describe some elements of this work on health information systems, which started in South Africa but has now spread to a wide range of developing countries. The authors describe the theoretical concept of flexible standards to support standardization processes in complex systems such as health care, and suggest an approach to implementing such standards in developing country settings that is sensitive to the local context, allowing changes to occur in small steps, but retaining a mechanism for scaling information systems across wider domains. 


\subsection{Power, Knowledge, and Control}

The links between power and knowledge and their effects on control were present implicitly in much of the research literature discussed earlier. However, an explicit focus on such elements was often missing, but is surely crucial to an increased understanding of global working in a non-flat world. Future research is needed to address questions about the power relations between outsourcing suppliers and vendors. With respect to global IS roll-out and generification processes, who controls the processes and to what extent are local interests and local knowledge ignored or given low priority? How do power and politics play out in global virtual teams and who are the winners and losers?

A further broad area for future work on globalization and ICTs from the perspective of power and control would take a critical approach and ask research questions about silent voices, namely those often not considered at all in the networks of the powerful. For example, global software outsourcing may benefit the elites in India and elsewhere, but is there any evidence of spin-off effects in other areas such as the use of ICTs within India to benefit a wider range of stakeholders (Krishna and Walsham 2005)? Is the global roll-out of systems a form of neo-colonialism when imposed on particular developing countries (Adam and Myers 2003)? Who is marginalized by the use of ICTs in global working? For example, on the latter question, Thompson (2004) shows how the effects of the World Bank's global knowledge forum can be taken to exclude in-country inputs and grassroots participation in the development agenda.

IS researchers studying global issues involving power, politics, development, and marginalization have already drawn on a range of related literatures on these topics but this cross-discipline approach could be extended further. For example, institutional theory has been suggested as potentially valuable to the IS field (Orlikowski and Barley 2001) but its application has been limited to date.Although not an IS study as such, Khan et al. (2007) provide a good illustration of detailed work based on institutional theory and the "dark side" of even the well-intentioned exercise of power in the context of globally distributed working. The authors describe a case study of institutional entrepreneurship concerned with removing child labor from soccer ball production in Pakistan but with unintended negative consequences on women stitchers in that country. A second body of literature of relevance to issues of power and politics, which has received little attention in the IS field, is that of development studies. Thompson (2007) argues that work on ICTs and development should make more effort to connect to the development studies literature, and thus for IS researchers to become better engaged with issues of practice and policy in developing countries.

\section{CONCLUSIONS}

This paper has argued that the new ICT-enabled world is not flat. Analyses of three specific areas of ICTs and global working have shown the importance of unevenness in areas such as cultural difference, the heterogeneity of work processes, the significance of local specificity, and the asymmetry of power relationships. Organizations are not well-integrated as some senior practitioners claim, but instead struggle to make ICTenabled global working effective. None of this argues against the importance of ICTs in 
the contemporary world, including the growing service-based component. Indeed, it could be argued that the increased emphasis on services makes the application of ICTs even more crucial since ICTs can be regarded as one of the primary transport systems for a globally-distributed service-based world.

There is an existing literature on ICTs and global working, but it remains relatively sparse to date. We can build on this research to further explore themes such as those identified in the previous section: shifting identity and cross-cultural working, globalization and standardization, and issues of power and control. We can try to connect better to other relevant literatures and disciplines such as those concerned with identity, culture, globalization, and development. Conducting in-depth research on ICTs and global working is not an easy task, due to issues such as time, cost, and complexity, but it offers the IS field a major opportunity to make a significant contribution to our understanding of crucial issues in our more globalized world.

\section{References}

Adam, M., and Myers, M. 2003. "Have You Got Anything to Declare? Neo-Colonialism, Information Systems, and the Imposition of Customs and Duties in a Third World Country," in Organizational Information Systems in the Context of Globalization, M. Korpela, R. Montealegre, and A. Poulymenakou (eds.), Boston: Kluwer Academic Publishers, pp. 101-116.

Ailon-Souday, G., and Kunda, G. 2003. "The Local Selves of Global Workers: The Social Construction of National Identity in the Face of Organizational Globalization," Organization Studies (24:7), pp. 1073-1096.

Appadurai, A. 1996. Modernity at Large: Cultural Dimensions of Globalization, New Delhi: Oxford University Press.

Avgerou, C. 2002. Information Systems and Global Diversity, Oxford, UK: Oxford University Press.

Beck, U. 2000. What Is Globalization?, Cambridge, UK: Polity Press.

Braa, J., Hanseth, O., Heywood, A., Mohammed, W., and Shaw, V. 2007. "Developing Health Information Systems in Developing Countries: The Flexible Standards Strategy," MIS Quarterly (31:2), pp. 381-402.

Brannen, M. Y., and Salk, J. E. 2000. "Partnering Across Borders: Negotiating Organizational Culture in a German-Japan Joint Venture," Human Relations (53:4), pp. 451-487.

Castells, M. 1996. The Rise of the Network Society ( $1^{\text {st }}$ ed.), Cambridge, UK: Blackwell Publishers Ltd.

Castells, M. 1997. The Power of Identity ( $1^{\text {st }}$ ed.), Cambridge, UK: Blackwell Publishers Ltd.

Castells, M. 1998. End of Millennium ( $1^{\text {st }}$ ed.), Oxford, UK: Blackwell Publishers Ltd.

Crowston, K., Sieber, S., and Wynn, E. (eds.). 2007. Virtuality and Virtualization, Boston: Springer.

Davenport, T. H. 1998 "Putting the Enterprise into the Enterprise System," Harvard Business Review, July-August, pp. 121-131.

D’Mello, M. 2005. “'Thinking Local, Acting Global': Issues of Identity and Related Tensions in Global Software Organizations in India," Electronic Journal of Information Systems in Developing Countries (22:2), pp. 1-20.

D'Mello, M. 2006. Understanding Selves and Identities of Information Technology Professionals: A Case Study from India, unpublished Ph.D. Dissertation, Faculty of Social Sciences, University of Oslo. 
D’Mello, M., and Sahay, S. 2007. "“I Am Kind of a Nomad Where I Have to Go Places and Places'...Understanding Mobility, Place and Identity in Global Software Work from India," Information and Organization (17:3), pp. 162-192.

Dubé, L., and Paré, G. 2001. "Global Virtual Teams," Communications of the ACM (44:12), pp. 71-73.

Friedman, T. 2005. The World is Flat: A Brief History of the Twenty-First Century, New York: Farrar, Straus and Giroux.

Gibson, C. B., and Gibbs, J. L. 2006. "Unpacking the Concept of Virtuality: The Effects of Geographic Dispersion, Electronic Dependence, Dynamic Structure, and National Diversity on Team Innovation," Administrative Science Quarterly (51:3), pp. 451-495.

Haraway, D. J. 1991. Simians, Cyborgs, and Women: The Reinvention of Nature, London: Free Association Books.

Hofstede, G. 1991. Cultures and Organizations: Software of the Mind, New York: McGrawHill.

Jagun, A., Heeks, R., and Whalley, J. 2007. "Mobile Telephony and Developing Country MicroEnterprise: A Nigerian Case Study," Working Paper No 29, Institute for Development Policy and Management, University of Manchester.

Joshi, S., Barrett, M, Walsham, G., and Cappleman, S. 2007. "Balancing Local Knowledge Within Global Organizations Through Computer-Based Systems: An Activity Theory Approach," Journal of Global Information Management (15:3), pp. 1-19.

Kankanhalli, A., Tan, B. C. Y., and Wei, K-K. 2007. "Conflict and Performance in Global Virtual Teams," Journal of Management Information Systems (23:3), pp. 237-274.

Kayworth, T. R., and Leidner, D. E. 2002. "Leadership Effectiveness in Global Virtual Teams," Journal of Management Information Systems (18:3), pp. 7-40.

Khan, F. R., Munir, K. A., and Willmott, H. 2007. "A Dark Side of Institutional Entrepreneurship: Soccer Balls, Child Labour and Postcolonial Impoverishment," Organization Studies (28:7), pp. 1055-1077.

Krishna, S., Sahay, S., and Walsham, G. 2004. "Managing Cross-Cultural Issues in Global Software Outsourcing," Communications of the ACM (47:4), pp. 62-66.

Krishna, S., and Walsham, G. 2005. "Implementing Public Information Systems in Developing Countries: Learning from a Success Story," Information Technology for Development (11:2), pp. 123-140.

Leamer, E. E. 2007. “A Flat World, a Level Playing Field, a Small World after All, or None of the Above? A Review of Thomas L. Friedman's The World is Flat," Journal of Economic Literature (XLV), pp. 83-126.

Majchrzak, A., Malhotra, A., Stamps, J., and Lipnack, J. 2004. "Can Absence Make a Team Grow Stronger?," Harvard Business Review, May, pp. 131-137.

Martins, L. L., Gilson, L. L., and Maynard, M. T. 2004. "Virtual Teams: What Do We Know and Where Do We Go from Here?," Journal of Management (30:6), pp. 805-835.

McAfee, A. P. 2006. "Enterprise 2.0: The Dawn of Emergent Collaboration," MIT Sloan Management Review (47:3), pp. 21-28.

Miscione, G. 2007. "Telemedicine in the Upper Amazon: Interplay with Local Health Care Practices," MIS Quarterly (31:2), pp. 403-425.

Nicholson, B., and Sahay, S. 2001. "Some Political and Cultural Issues in the Globalization of Software Development: Case Experience from Britain and India," Information and Organization (11:1), pp. 25-43.

Orlikowski, W. J., and Barley, S. R. 2001. "Technology and Institutions: What Can Research on Information Technology and Research on Organizations Learn from Each Other?," MIS Quarterly (25:2), pp. 145-165.

Palmisano, S. 2006. "Multinationals Have Been Superseded," Financial Times, June 12, p. 19. 
Pan, S. L., and Leidner, D. E. 2003. "Bridging Communities of Practice with Information Technology in Pursuit of Global Knowledge Sharing," Journal of Strategic Information Systems (12:1), pp. 71-88.

Pollock, N., Williams, R., and Procter, R. 2003. "Fitting Standard Software Packages to NonStandard Organizations: The Biography of an Enterprise-Wide System," Technology Analysis \& Strategic Management (15:3), pp. 317-332.

Pollock, N., Williams, R., and D'Adderio, L. 2007. "Global Software and its Provenance: Generification Work in the Production of Organizational Software Packages," Social Studies of Science (37:2), pp. 254-280.

Qureshi, S., and Zigurs, I. 2001. "Paradoxes and Prerogatives in Global Virtual Collaboration," Communications of the ACM (44:12), pp. 85-88.

Rolland, H. H., and Monteiro, E. 2002. "Balancing the Local and the Global in Infrastructural Information Systems," The Information Society (18:2), pp. 87-100.

Sahay, S., Nicholson, B., and Krishna, S. 2003. Global IT Outsourcing: Software Development Across Borders, Cambridge, UK: Cambridge University Press.

Tan, B. C. Y. 2007. "Leveraging Virtual Communities for Global Competitiveness," Journal of Global Information Management (15:3), pp. i-iii.

Thompson, M. 2004. "Discourse, 'Development' and the 'Digital Divide': ICT and the World Bank," Review of African Political Economy (31:9), pp. 103-123.

Thompson, M. 2007. "ICT and Development Studies: Towards Development 2.0," Working Paper 27/2007, Judge Business School, University of Cambridge (http://www.jbs.cam.ac.uk/ research/working_papers/2007/wp0727.pdf).

Urry, J. 2000. "Mobile Sociology,” British Journal of Sociology (51:1), pp. 185-203.

Walsham, G. 2001. Making a World of Difference: IT in a Global Context, Chichester, UK: Wiley.

Walsham, G. 2002. "Cross-Cultural Software Production and Use: A Structurational Analysis," MIS Quarterly (26:4), pp. 359-380.

\section{About the Author}

Geoff Walsham is a Professor of Management Studies (Information Systems) at Judge Business School, University of Cambridge. In addition to Cambridge, he has held academic posts at the University of Lancaster in the UK where he was Professor of Information Management, the University of Nairobi in Kenya, and Mindanao State University in the Philippines. His teaching and research is focused on the question: Are we making a better world with information and communication technologies? He was one of the early pioneers of interpretive approaches to research on information systems. Geoff is currently a senior editor of MIS Quarterly. He can be reached at g.walsham@jbs.cam.ac.uk. 